\title{
Corrigendum: Children's perceptions of democratic values: Implications for democratic citizen education
}

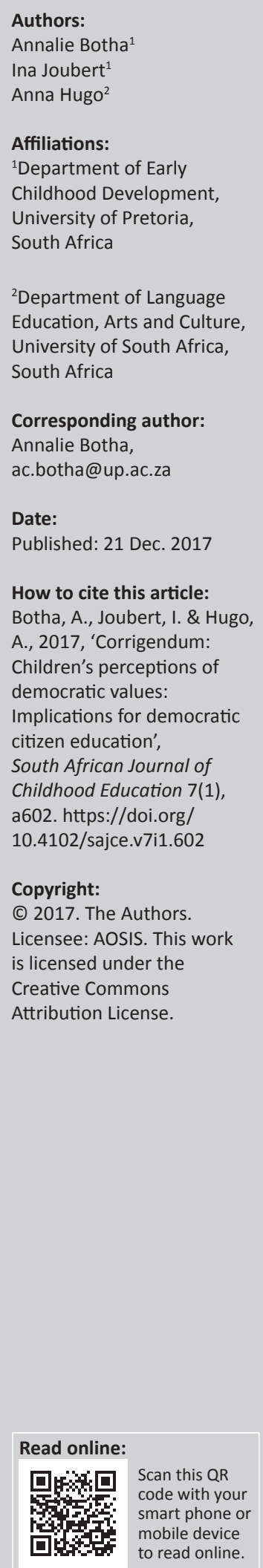

In the version of this article initially published, Anna Hugo's affiliation was incorrectly listed as the Department of Language Education, Arts and Culture, University of Pretoria. Her correct affiliation is the Department of Language Education, Arts and Culture, University of South Africa, South Africa. The error has been corrected in the PDF version of the article. The author apologises for any inconvenience that this omission may have caused. 